\title{
Regulatory Compliance in Lake Victoria Fisheries
}

\author{
By \\ Håkan Eggert, \\ Department of Economics, Göteborg University, Box 640, SE-405 30 \\ Göteborg, Sweden, Email: Hakan.Eggert@economics.gu.se \\ Razack B Lokina, \\ National Environment Management Council (NEMC), Box 63154, \\ Dar-Es-Salaam, Tanzania ${ }^{1}$
}

\begin{abstract}
This paper analyzes the causes for regulatory compliance using traditional deterrence variables and potential moral and social variables. We use self-reported data from Tanzanian artisanal fishers in Lake Victoria. The results indicate that fishers adjust their violation rates with respect to changes in the probability of detection and punishment, but they also react to legitimacy and social variables. A small group of persistent violators react neither to normative aspects nor to traditional deterrence variables, but systematically violate the regulation and use bribes to avoid punishment.
\end{abstract}

JEL classification: K42, L51, Q22

Keywords: compliance, fishery, Lake Victoria, legitimacy, normative, deterrence

\footnotetext{
${ }^{1}$ The authors are grateful for comments from Claire Armstrong, Fredrik Carlsson, Olof Johansson-Stenman, Peter Martinson, Thomas Sterner, Ragnar Tveterås, seminar participants at the Göteborg University, and the participants at the Nordic Conference in Development Economics, 2004. Thanks to Jon Sutinen and K. Kuperan for providing their questionnaire. Financial assistance from the Swedish International Development Agency (SIDA) is gratefully acknowledged.
} 


\section{Introduction}

Poor people are frequently compelled to exploit their surroundings for short-term survival, and make up the group most regularly exposed to natural resource degradation (World Bank, 2002). Natural resources are often of a common pool resource type, which implies problems with overexploitation that sometimes are hard to manage, even in welldeveloped countries. Fish is a major source of protein for many poor people (UNEP, 2002) and a resource where the previous discussion applies. Almost half of the world's landings are from tropical waters (Pauly, 1996) and from countries where development is at a low or medium level. These fisheries are frequently open access with no restrictions on entry or total catch, and regularly lack even rudimentary tools for management, such as landing records. In such poor institutional settings, how individuals act and interact is of utmost importance to whether or not fish stocks can be sustained.

Predictions from the traditional economics of crime model are quite pessimistic. The seminal contribution by Becker (1968) basically outlines a choice between the legal and the illegal option. The major determinant for this choice is the expected payoff, which simply put, is a function of the risk of being punished, the expected punishment and the net profit from violating the law. On the one hand, the management implications from the deterrence model are that monitoring must increase and that penalties must be higher. ${ }^{2}$ On the other hand, it is socially desirable that enforcement policy creates marginal deterrence, ${ }^{3}$ which rules out the use of severe penalties for relatively mild violations such as fishing a closed area or landing fish below minimum size. Monitoring and enforcement of fisheries is costly and accounts for 25-50\% of the public expenditures on fisheries (Sutinen and Kuperan,

\footnotetext{
${ }^{2}$ Becker (1968) assumes that the individual wants to maximize utility and the utility function may of course include moral and social aspects. Becker refers to "his willingness to commit an illegal act", which seems to be exogenous; in general, little attention is given to this aspect in policy conclusions from the deterrence model. ${ }^{3}$ The term was first used by Stigler (1970) and refers to those not deterred from doing harm should have a reason to moderate the level of harm they cause, i.e., most sanctions should be less than maximal.
} 
1999), which raises doubt as to whether increased monitoring and enforcement leads to social net benefits. Recent research in the social sciences also extends the deterrence model to include normative aspects of complying with the law such as personal morality and legitimacy (Tyler, 1990).

This paper analyzes the causes of regulatory compliance in a developing country context. In addition to traditional deterrence variables such as risk of detection and expected gains from violation, we explore potential reasons for following the rules such as being moral and doing the right thing, obeying the rules due to peer pressure from other fishers, perceiving the regulation as legitimate, and perceiving that they (the fishers) have been involved in the regulation process. We use self-reported data from Tanzanian artisanal fishers in Lake Victoria and focus our analysis on the minimum mesh-size regulation. The results indicate that fishers adjust their violation rate with respect to changes in deterrence variables such as probability of detection and punishment. Fishers also react to legitimacy and social variables, which inter alia means complying more when they perceive the regulation to be legitimate as well as when they are influenced by peer groups. We also find a small group of persistent violators who appear to react neither to normative aspects nor to traditional deterrence variables. These fishers systematically violate the mesh-size regulation and when arrested, bribe their way out of punishment.

\section{Lake Victoria Fisheries}

Lake Victoria is the worlds' second largest and Africa's largest fresh water body. Kenya, Uganda and Tanzania share Lake Victoria; the Tanzanian section encompasses 49\% of the lakes' surface, while the Ugandan and Kenyan sections encompass $45 \%$ and $6 \%$, respectively. The Nile perch was introduced to Lake Victoria in the 1950s and experienced explosive population growth in the 1970s. Its introduction led to increasing landings and a 
new source of cheap protein, while severely reducing biological diversity; the original 350400 species of fish in the early 1900s are now fewer than 200 (Brundy and Pitcher 1995; Kudhongania and Chitamwebwa 1995). Today there are three commercially important species: Nile perch, Dagaa and the Tilapia, which constitute 60\%, 20\%, and 10\%, respectively, of Tanzania's total Lake Victoria landings (Ssentongo and Jlhuliya, 2000). The open access nature of the lake fisheries combined with rapid population growth, lack of employment opportunities and the increasing Nile perch market, have led to an increasing number of fishers and a depletion of fish stocks (Ikiara, 1999). This decline concerns onethird of the population or about 30 million people supported by the lake basin in Kenya, Tanzania and Uganda (LVFO, 1999).

The Nile perch is exported to Europe, Asia and North America. Processing and export industries were established in Kenya and Uganda during the 1980s and in Tanzania in the early 1990s. Dagaa is to a large extent processed domestically for household consumption and animal feed (fishmeal). Small-scale fishing units generate almost all of the fishing effort on the lake. These fishers use boats or canoes that are fitted with outboard motors or a sail/paddle and hold a total crew of two to six people, including the skipper. Fishers place their nets in the late afternoon and retrieve them in the morning. Dagaa is fished at night when the moon is dark with pressure lamps to attract the fish. Due to the need for lamps, the choice of Dagaa fishing locations is limited to sheltered environments and areas fishers can easily reach from their own beaches.

The current regulation requires fishers to pay an annual fee of approximately USD 20, which is equivalent to the gross revenues from 1-2 days of fishing. Several minor restrictions exist, but the most important is the minimum gillnet mesh size, which is five inches (125 $\mathrm{mm})$ for Nile perch and Tilapia, and $0.4 \mathrm{inch}(10 \mathrm{~mm})$ for Dagaa. There are 63 Tanzanian fishery officers who act as both extension and enforcement officers (LVFO, 2004). The 
focus of this study is on gillnet fishers, who either target Nile perch and Tilapia or Dagaa. As a response to the declining catch per unit of effort, fishers have increased their number of nets and the use of a mesh size smaller than that prescribed. In the short run, a smaller mesh size leads to a larger catch, but the long-run implication is a smaller stock and smaller sustainable landings. Reports in Tanzanian district fishery offices show that fishers' compliance with regulations is poor, with the most violated regulations being the use of an illegal mesh size, beach seine, and fishing in closed areas (Wilson, 1995).

In 1998, the Tanzanian Government, supported by the World Bank, introduced local management units commonly known as Beach Management Units (BMUs), through the Lake Victoria Environmental Management project. The aim is to enhance community participation in surveillance and management and to put an end to detrimental fishing practices such as using poison or dynamite. The BMU leaders do not have any legal authority, but can point out culprits to the enforcement officials. According to local fishery officers (personal communication) the BMUs have been successful in reducing the use of poison and dynamite. A recent study also indicates that they have led to increased efficiency in both Nile perch and Dagaa fisheries (Lokina, 2004), which is possibly explained by fishers exchanging information and learning from each other at the regular BMU meetings.

\section{Survey Description and Data}

The data for this study was collected using a questionnaire during April-June 2003. The questionnaire was administered in face-to-face interviews with vessel skippers with an assurance of individual anonymity and confidentiality. Consideration was taken in the design of the questionnaire to maximize the likelihood of honest responses, in particular regarding questions about the fishers' own violation behavior. The questionnaire was administered in 
collaboration with the staffs of the Tanzania Fisheries Research Institute (TAFIRI). ${ }^{4}$ A pilot survey was conducted on three landing sites, i.e., beaches that were not in the sample, followed by revisions and minor changes. The respondents were asked about their own violation rates during the last twelve-month period and gave answers such as "zero," "one month," "two to three months" or "twelve months," etc. We identified three subgroups, which we label non-violators, alternating violators, and persistent violators, with zero, one to ten months, and eleven months or more of violation, respectively. Zero violation means that the respondent has not broken violations for the past twelve months; one month means that in the past twelve months he broke violations only one month, and so on. Sixty-minute interviews were carried out individually and included questions on respondent attitudes and perceptions about the legitimacy of mesh size regulation, social pressures to comply, attitudes towards violation and feelings of obligation to comply. ${ }^{5}$ Questions related to legitimacy concerned the perceived effectiveness and fairness of mesh size regulations, the legitimacy of management institutions, and the involvement of fishers in the management. These questions were statements for which the respondents ranked their level of agreement on a four-digit scale, where a higher score means stronger agreement. Socioeconomic characteristics of the fisher were recorded either directly, (e.g., age and experience as a skipper, household size), or where appropriate, using an interval scale, e.g., household income was recorded in this way to minimize the concern of confidentiality and accuracy. We also included questions related to the subjective probability of detection, arrest and conviction. Respondents were asked to report their own compliance behaviors as well as their perceptions of other fishers' compliance behavior at the same beach. Further, questions related to the level of fishers' involvement in policy formulation and enforcement were

\footnotetext{
${ }^{4}$ The staff at TAFIRI in Mwanza has long working experience in the field and has regular contact with fishers around the lake. Most if not all fishers are aware of the staff as not being part of the enforcement officials. ${ }^{5}$ The questionnaire design was to a large extent based on the questionnaire used by Kuperan and Sutinen (1998).
} 
asked. Self-reports may imply a risk of biased data, especially as respondents were asked about their own illegal activities, but the overall impression was that the fishers were cooperative and generous with their answers, including their own violations. Nonetheless, the potential magnitude of penalties in the case of conviction seemed to be impossible for many of the fishers to assess, which led to exclusion of that question.

\section{Methodology}

The original deterrence model by Becker (1968) led to a large number of empirical papers testing the hypothesis (starting with Erlich, 1973; Gaviria, 2000 is a recent extension), which by and large confirmed the theory. Whether the deterrence conclusion is confirmed has been debated, however, and one level of critique is methodological. This critique stresses that the theory is developed on the individual level, while much of the empirical work is based on some level of aggregation. If crime rate is defined as crime per capita, and probability to be arrested is measured as the ratio of arrests to crimes, we have the number of crimes in the denominator of the independent variable and in the numerator of the dependent variable, which can imply spurious correlation. Similarly, if notorious criminals are arrested and kept in custody, it implies a lower crime level, but the negative correlation between crime and arrest rates is not due to the risk of being arrested, but to the actual captivity. Finally, more crimes lead to more expenditures on law enforcement, which implies a simultaneous relationship between crime and enforcement levels. Manski (1978) suggested survey-collected individual self-reports as a means of avoiding these problems, since each individual will have a negligible impact on each of the three objections raised. Furlong (1991) applied these ideas to Canadian fishers and found the fishers to be most sensitive to changes in the likelihood of detection, while fines appeared to create the greatest deterrence among various penalties. 
Social science research on why people follow the law has been dominated by the instrumental perspective, which is based on deterrence literature and reaches the same policy conclusions as the economics research following the Becker approach. However, given the weak deterrent threat facing people for minor violations, this approach cannot explain why the vast majority of people act in a way consistent with the law (Robinson and Darley, 1997). Recent contributions to legal thought, which to a large extent are revivals of older ideas, provide several suggestions. One reason for following the rules is to avoid the disapproval of your social group, another is that you see yourself as a moral being who wants to do the right thing (Robinson and Darley, 1997). A third factor is legitimacy, which means that the individual feels that the authority enforcing the law is entitled to dictate behavior. This in turn depends on whether individuals think that the law is fair and applied in a fair manner. Whether legitimacy is maintained or undermined is dependent on people's experiences with legal authorities (Tyler 1990).

Enforcement in fisheries has been a fairly neglected area (Sutinen and Hennessey, 1986). The early contributions are theoretical and deal with optimal stock if non-zero enforcement costs are introduced (Sutinen and Andersen, 1985; Milliman, 1986) and the choice of optimal government policy (Anderson and Lee, 1986). The first empirical study confirmed the deterrence model showing that an increased risk of detection and conviction reduce the violation rate in a fishery (Sutinen and Gauvin, 1989). The simple deterrence model predicts that most fishers will violate the regulation. The risk of detection is low, fines are modest, and the profits from violation are substantial. Still, a vast majority of fishers in various fisheries seem to comply with the regulation, which contradicts the predictions based on this model (e.g. Sutinen and Kuperan, 1999; Eggert and Ellegård, 2003). Extended analysis is therefore necessary to include both the instrumental and the normative perspective. The empirical evidence from such an approach is mixed. Kuperan and Sutinen 
(1998) found that compliance in a Malaysian fishery depended on the tangible gains and losses, as well as the moral development, legitimacy, and behavior of others in the fishery. Hatcher et al. (2000) reached similar conclusions while Hatcher and Gordon (2005) found less evidence in favor of normative influence on fisher compliance, while again confirming the deterrence effect. These studies deal with trawl fisheries where the capital input is substantial, while our study is the first to analyze artisan fishers. The fishers in our sample all have low levels of capital input, i.e., they operate simple open wooden-hulled vessels; almost half of the fishers lack motors and have to use sails or paddles to propel their vessels. The theoretical model that we follow is the one which extends the neoclassical utilitarian model of individual violation behavior to include normative and social judgments (Sutinen and Kuperan, 1999; Hatcher and Gordon, 2005), of the form

$V_{\mathrm{i}}=\mathrm{f}\left(\mathrm{Y}_{\mathrm{i}}, \mathrm{D}_{\mathrm{i}}, \mathrm{M}_{\mathrm{i}}, \mathrm{L}_{\mathrm{i}}, \mathrm{S}_{\mathrm{i}} \mathrm{X}\right)$,

where $V_{i}$ is a self-reported violation rate, $\mathrm{Y}_{\mathrm{i}}$ is the variable related to the financial incentive to violate, $D_{i}$ is a vector of deterrence variables such as the probability of detection and the expected fine if detected, $\mathrm{M}_{\mathrm{i}}$ is a vector of variables measuring moral obligation to comply, $\mathrm{L}_{\mathrm{i}}$ is a vector of variables trying to capture perceived regulatory legitimacy, $\mathrm{S}_{\mathrm{i}}$ is a vector of social influence variables and X measure personal characteristics. The hypotheses of interest in this study therefore are:

$\frac{\partial V_{i}}{\partial Y_{i}}>0, \frac{\partial V_{i}}{\partial D i}<0, \frac{\partial V_{i}}{\partial M_{i}}<0, \frac{\partial V_{i}}{\partial L_{i}}<0, \frac{\partial V_{i}}{\partial S_{i}}<0$ 
The main assumption here is that higher measurements of $\mathrm{M}_{\mathrm{i}}, \mathrm{S}_{\mathrm{i}}$ and $\mathrm{L}_{\mathrm{i}}$ correspond, respectively, to: stronger moral judgments against violation, perceptions of stronger social norms against violation and increasingly positive judgments concerning legitimacy of regulations and of the regulating authorities. We do not have prior predictions of the direction of the $\mathrm{X}$ variables.

\subsection{Econometric specification}

The point of departure is that the dependent variable, violation, is a latent variable that describes the degree to which fishers are in violation of the mesh size regulation. The violation is measured in the number of months in which the fisher violated the mesh size regulation. The values therefore range from 0 for non-violators to 12 months for persistent violators. In general we specify our model as:

$V_{i}=X_{i}^{\prime} \beta+\varepsilon$,

where $\mathrm{X}$ is a vector of an observable variable possibly governing $V$, and $\varepsilon$ is normally distributed with mean 0 , and standard deviation $\sigma$. Data on $V$ are only observed when $V=j$ for some $j$ in $(0,1,2)$, where 0 is for non-violators, 1 is for those who violated for one to ten months (occasional violators) and 2 is for those who violated for eleven months or more (persistent violators). We are interested in why fishers may choose to comply rather than violate the rules and vice versa. It is often found that for any regulation there is a small subgroup of persistent violators (Feldman, 1993), a condition which seems also to exist in fisheries (Kuperan and Sutinen, 1998). Further, those who always obey (violate) the rules may on some occasions be attracted to deviate from their normal behavior, but lack the 
possibility to do so. A simple reason could be that they do not possess the illegal (legal) gear, which implies that the model will fit those who actually alternate between legal and illegal acts. Excluding the others would be a waste of information and lead to biased estimates, as there is self-selected participation. In this study we use the generalized Heckman procedure (Heckman, 1979). In the first step, the probability that a given individual fisher will violate the mesh size regulation is determined from an ordered probit model using all available observations in the three categories. In the second step, the inverse Mills ratio term ${ }^{6}$ is used as an instrument variable in the regression on the sub-sample of occasional violators to correct for bias. Using the least square method has the advantage that it allows us to directly interpret the parameter in the selection model as a conditional marginal effect. The ordered probit model is:

$V^{*}=x_{i}{ }^{\prime} \beta+u$

$$
V=\left(\begin{array}{l}
0 \text { if } \mathrm{v}^{*} \leq \mu_{1} \\
1 \text { if } \mu_{1}<v^{*}<\mu_{2} \\
2 \text { if } \mathrm{v}^{*} \geq \mu_{2}
\end{array}\right)
$$

where $V^{*}$ is not observed and $V$ is its observed counterpart, $x_{i}$ is a vector of explanatory variables, $\mu_{1}$ and $\mu_{2}$ are threshold parameters to be estimated with the $\beta \mathrm{s}$ ', the subscript $i$ is the index of the individual and the error term $u$ is distributed as standard normal (Greene, 2000).

${ }^{6} \lambda(x)=\phi(X) /[1-\Phi(X)]$, where $X$ is a vector of regressors related to the violation decision, $\phi$ is the standard normal probability density function, and $\Phi$ is the standard normal cumulative distribution function. 


\section{Results}

The descriptive statistics are reported in Table 1. The sample consists of 459 fishers of whom $45 \%$ are non-violators, $47 \%$ are occasional violators and $8 \%$ persistent violators. The overall violation rate is $29 \%$, which is substantially higher than the rate reported in previous studies (see Sutinen and Kuperan, 1999), and the persistent violators are responsible for 30\% of the violations. ${ }^{7}$

\footnotetext{
${ }^{7}$ We assume that the number of trips per month and year are equally distributed among the three groups.
} 
Table 1: Descriptive Statistics of Variables Included in the Estimations

\begin{tabular}{|c|c|c|c|}
\hline Name & Variable description & Mean & Std dev. \\
\hline \multicolumn{4}{|c|}{ Socio-economic variables } \\
\hline AGE & Age of the skipper & 33.36 & 9.43 \\
\hline EDUCATION & Number of years in school & 6.45 & 2.24 \\
\hline SKIP_EXP & Years of fishing experience as a skipper & 4.81 & 4.25 \\
\hline SOURCE & If fishing is the main source of income $(1 / 0)$ & 0.86 & 0.35 \\
\hline OWNERPC & The owner is onboard either as crew or as skipper $(1 / 0)$ & 0.38 & 0.49 \\
\hline MOTOR & Dummy for boat outboard motor & 0.54 & 0.50 \\
\hline NILE PERCH & Dummy for targeting Nile perch & 0.80 & 0.37 \\
\hline MWANZA & Dummy for Mwanza region & 0.39 & 0.49 \\
\hline MARA & Dummy for Mara region & 0.31 & 0.46 \\
\hline \multicolumn{4}{|c|}{ Deterrence variables } \\
\hline SEEN & Number of times the unit has seen the officials when landing & 0.70 & 0.46 \\
\hline DCPUM & $\begin{array}{l}\text { Expected difference in value ('000Tshs) of catch per } \\
\text { crewmember between illegal and legal. }\end{array}$ & 30.21 & 36.8 \\
\hline ARRESTED & The number of arrests during the past year & 1.33 & 1.75 \\
\hline PROBD & Subjective probability of being detected & 0.37 & 0.30 \\
\hline PROBDA & Subjective probability of being arrested given detection & 0.58 & 0.32 \\
\hline PROBDAC & Subjective probability of being taken to court given arrest & 0.50 & 0.35 \\
\hline PROBDACG & Subjective probability of being found guilty given court & 0.65 & 0.32 \\
\hline \multicolumn{4}{|c|}{ Social variables } \\
\hline BMU & The existence of an active beach management unit (1/0) & 0.47 & 0.50 \\
\hline PERCOMP & Percentage of fishers perceived to be violating the regulation & 0.41 & 0.35 \\
\hline ATTIT & Peer attitudes towards violation ( $1=$ wrong; $0=$ not wrong $)$ & 0.36 & 0.19 \\
\hline \multicolumn{4}{|c|}{ Legitimacy variables } \\
\hline FVIEW & Fishers' views are considered in regulation design (1/0) & 0.69 & 0.46 \\
\hline RIGHT & $\begin{array}{l}\text { The government is doing the right thing by imposing the } \\
\text { regulation }(1 / 0)\end{array}$ & 0.60 & 0.65 \\
\hline NOCONSIST & Regulation is not enforced consistently (1/0) & 0.84 & 0.36 \\
\hline JUST & The mesh size regulation is a fair regulation $(1 / 0)$ & 0.74 & 0.44 \\
\hline EVERYONE & The mesh size regulation improves the well-being of all $(1 / 0)$ & 0.54 & 0.47 \\
\hline WELLEST & $\begin{array}{l}\text { The mesh size regulation improves the well-being of a few } \\
(1 / 0)\end{array}$ & 0.37 & 0.42 \\
\hline NOTEFF & The mesh size regulation is not an effective measure $(1 / 0)$ & 0.41 & 0.49 \\
\hline PENALFIT & The penalty given to violators 'fits' the offence $(1 / 0)$ & 0.56 & 0.49 \\
\hline ADEQUATE & The enforcement in your fishing area is adequate $(1 / 0)$ & 0.48 & 0.50 \\
\hline NODETECT & Many of the violators are not detected $(1 / 0)$ & 0.56 & 0.50 \\
\hline
\end{tabular}


The deterrence variables include aspects such as the expected gain per unit effort from violating, how often officials have been seen, a dummy for previous arrest, and the respondent's subjective judgment of probability of detection, of arrest, of being taken to court, and of being found guilty. The probabilities are increasing, which is intuitive; those who are more likely to be convicted will more likely be brought through the legal procedures. The probability of being taken to court is an exception and is lower than that of being arrested. This is the stage where bribes are most likely to occur and it may be that the respondents have adjusted for the use of bribes. If we disregard the effects of bribes, the average perceived overall probability of being detected and punished is $7 \%$, which is substantially larger than the "below 1 percent, and often at or near zero" found in previous studies (Sutinen and Kuperan, 1999). The social and legitimacy variables were all measured by a four-digit scale. However, in the final analysis these answers were recoded as dummy variables with levels three and four being one and levels one and two being zero, where one indicates that the fisher agrees with the statement. The correlation between all of the used variables was estimated, but did not exceed 0.54 . 
Table 2. Ordered Probit Probality of the Violation Category Model

\begin{tabular}{|c|c|c|}
\hline IVariable & Coefficient & $\mid \mathrm{P}[|\mathrm{Z}|>\mathrm{z}]$ \\
\hline Constant & $-1.050 * *$ & 0.029 \\
\hline EDUCATION & $0.060 * *$ & 0.025 \\
\hline SKIP_EXP & 0.008 & 0.582 \\
\hline OWNERPC & $-0.458 * * *$ & 0.000 \\
\hline MOTOR & $0.585 * * *$ & 0.000 \\
\hline NILE PERCH & 0.022 & 0.893 \\
\hline MWANZA & $0.590 * * *$ & 0.000 \\
\hline MARA & 0.061 & 0.702 \\
\hline \multicolumn{3}{|c|}{ Deterrence variables } \\
\hline SEEN & 0.054 & 0.232 \\
\hline DCPUM & $0.007 * * *$ & 0.000 \\
\hline PROBD & 0.118 & 0.558 \\
\hline PROBDA & -0.027 & 0.887 \\
\hline PROBDAC & -0.225 & 0.169 \\
\hline PROBDACG & -0.033 & 0.859 \\
\hline \multicolumn{3}{|l|}{ Social variables } \\
\hline SOURCE & 0.071 & 0.678 \\
\hline $\mathrm{BMU}$ & 0.137 & 0.260 \\
\hline PERCOMP & $0.342 * *$ & 0.042 \\
\hline ATTIT & 0.307 & 0.298 \\
\hline \multicolumn{3}{|c|}{ Legitimacy variables } \\
\hline FVIEW & -0.178 & 0.170 \\
\hline RIGHT & -0.024 & 0.782 \\
\hline NONCONSIST & 0.002 & 0.991 \\
\hline JUST & $-0.261 * *$ & 0.050 \\
\hline EVERYONE & -0.229 & 0.110 \\
\hline WELLEST & $0.437 * * *$ & 0.004 \\
\hline NOTEFF & -0.174 & 0.150 \\
\hline ADEQUATE & $-0.321 * * *$ & 0.009 \\
\hline NODETECT & 0.181 & 0.122 \\
\hline PENALFIT & $0.254 * *$ & 0.035 \\
\hline$\mu$ & $1.795 * * *$ & 0.000 \\
\hline \multicolumn{2}{|c|}{ Number of observations } & 459 \\
\hline \multicolumn{2}{|c|}{ Log likelihood function } & -368.41 \\
\hline \multicolumn{2}{|c|}{ Prob $[$ chiSqd] $>$ value } & 0.000 \\
\hline
\end{tabular}

The results of the first stage ordered probit model are presented in Table 2. A highly significant estimate of $\mu$ indicates that the three categories in the response are indeed ordered (Liao, 1994). In the model, the dependent variable is an ordered rank of violation frequency where non-violation has a rank of zero, one to ten months of violation has a rank of one, and eleven months or more during the last twelve month period receives a rank of 
two. ${ }^{8}$ Many of the variables are statistically significant and significant variables can be found in all of the four variable subgroups, i.e., socioeconomic, deterrence, social and legitimacy variables.

Table 3 Marginal Effects of Significant Variables.

\begin{tabular}{|c|c|c|c|}
\hline & Non-Violators & Occasion violators & Persistent violators \\
\hline Variables & & Coefficient & \\
\hline \multicolumn{4}{|c|}{ SOCIO-ECONOMIC VARIABLES } \\
\hline EDUCATION & $-0.024 * *$ & $0.017 * *$ & 0.006 \\
\hline OWNERPC & $0.178 * * *$ & $-0.126 * * *$ & -0.052 \\
\hline MOTOR & $-0.228 * * *$ & $0.167 * * *$ & $0.061 * *$ \\
\hline MWANZA & $-0.226 * * *$ & $0.156^{* * *}$ & $0.070 * *$ \\
\hline \multicolumn{4}{|c|}{ Deterrence variables } \\
\hline DCPUM & $-0.003 * * *$ & $0.002 * * *$ & 0.001 \\
\hline \multicolumn{4}{|l|}{ Social variables } \\
\hline PERCOMP & $-0.135 * *$ & $0.099 * *$ & 0.036 \\
\hline \multicolumn{4}{|c|}{ Legitimacy variables } \\
\hline JUST & $0.103 * * *$ & $-0.078 * * *$ & -0.025 \\
\hline WELLEST & $-0.173 * * *$ & $0.134 * * *$ & 0.038 \\
\hline ADEQUATE & $0.126 * * *$ & $-0.092 * * *$ & -0.034 \\
\hline PENALFIT & $-0.100 * * *$ & $0.074 * * *$ & 0.026 \\
\hline
\end{tabular}

***, **, * indicate significance at the $1 \%, 5 \%$ and $10 \%$ levels, respectively.

In Table 3 we present the marginal effects for the statistically significant variables, which measure the increased (decreased) probability that the fisher would have been in the violation category, given one more unit of the explanatory variable with the other variables held at their mean. For the binary variables, the interpretation is the increase (decrease) in probability if the binary variable is equal to one. For example, the marginal value for nonviolation for education is -0.024 , which indicates that the probability for a fisher being a non-violator will decrease by $2 \%$ for every extra year of schooling he gets. The probability of being in the group of persistent violators is higher if the fisher possesses a motor and is

\footnotetext{
${ }^{8}$ Several cut-off points were tested without any major difference in the parameter estimates or the level of significance.
} 
from the Mwanza region. Otherwise, explanatory variables are not significant for this group. Whether a fisher always obeys the regulations is significantly indicated by a number of variables. More education, being from Mwanza, and possession of an outboard motor imply a reduced probability of always obeying the law, while having the owner onboard a vessel supports non-violation. Among the deterrence variables, only DCPUM is significant, which indicates that if the expected gains between legal and illegal behavior are increasing, then more non-violators are likely to become alternating violators.

Several of the social and legitimacy variables are significant, indicating that these variables have an impact on the decision to be a non-violator or to consider breaking the rules. The significant variable $P E R C O M P$ indicates that the higher the perceived percentage of fishers violating, the lower the probability for the fisher to remain a non-violator. Similarly, if fishers think that mesh size regulation improves the well-being of a few wellestablished fishers (WELLEST), they are likely to be alternating violators. If the mesh size regulation is seen as a fair regulation (JUST) and the enforcement in their fishing area is ADEQUATE, fishers are likely to be non-violators. The PENALFIT variable has an unexpected significant positive sign for alternating violators, indicating that fishers who beleive that the penalty fits the offense are more prone to break the rule. The study of Malaysian trawl fishers experience a similar result where violators think that the government is right in imposing a regulation and that the enforcement is adequate. Kuperan and Sutinen (1998) suggest that weak enforcement combined with high social and moral compliance increases the marginal value of violation, which explains why violators are in favor of the measures. The parallel to the Tanzanian fishers is that the violators enjoy better returns from violating when not all fishers violate due to a suitable penalty. Adding to this can be that non-violators think that the penalties are too low while violators think they are low enough 
to make violation profitable. We have no follow-up questions on these issues and as noted earlier, many fishers found it hard to assess penalties in the case of conviction.

Table 4: Least Squares Estimates of Violation Frequency.

\begin{tabular}{|c|c|c|}
\hline Variable & Coefficient & P-Value \\
\hline Constant & $1,115 * * *$ & 0,000 \\
\hline \multicolumn{3}{|l|}{ Socio-economic variables } \\
\hline $\mathrm{AGE}$ & $-0,005$ & 0,195 \\
\hline SKIP_EXP & $0,012 * *$ & 0,014 \\
\hline NILE PERCH & $-0,505 * * *$ & 0,000 \\
\hline MWANZA & $-0,055$ & 0,415 \\
\hline MARA & $0,142 * *$ & 0,041 \\
\hline \multicolumn{3}{|l|}{ Deterrence variables } \\
\hline SEEN & $-0,153 * * *$ & 0,010 \\
\hline DCPUM & $0,002 * *$ & 0,013 \\
\hline ARRERATE & $-0,319 * * *$ & 0,004 \\
\hline PROBD & $-0,152 *$ & 0,066 \\
\hline PROBDA & $-0,151 *$ & 0,054 \\
\hline PROBDAC & $-0,062$ & 0,370 \\
\hline PROBDACG & $-0,121$ & 0,125 \\
\hline \multicolumn{3}{|l|}{ Social variables } \\
\hline $\mathrm{BMU}$ & $-0,043$ & 0,396 \\
\hline PERCOMP & $0,208 * * *$ & 0,004 \\
\hline ATTIT & $-0,117$ & 0,344 \\
\hline \multicolumn{3}{|l|}{ Legitimacy variables } \\
\hline RIGHT & $-0,057$ & 0,205 \\
\hline FVIEW & $-0,087 *$ & 0,101 \\
\hline NONCONSIST & 0,049 & 0,453 \\
\hline JUST & $-0,015$ & 0,792 \\
\hline EVERYONE & $-0,101 *$ & 0,084 \\
\hline NOTEFF & 0,026 & 0,598 \\
\hline$\lambda$ (Selectivity correction) & $0,101 * * *$ & 0,011 \\
\hline Adjusted R-squared & \multicolumn{2}{|c|}{0,360} \\
\hline D-W Statistic & \multicolumn{2}{|c|}{1,693} \\
\hline Number of Observations & \multicolumn{2}{|c|}{216} \\
\hline
\end{tabular}

$* * *, * *, *$ indicate significance at the $1 \%, 5 \%$ and $10 \%$ levels, respectively.

In Table 4 we report the results of the corrected least square estimation of the violation rate.

There is evidence that participation is positively selected, since the lambda $(\lambda)$ is positive and statistically significant, which is now being adjusted for. From the socio-economic variables we see that fishers from the Mara region or with longer skipper experience tend to violate more. Those who target Nile perch violate to a lesser extent, which is expected, since 
Nile perch fishers supply the fish processing factories and these factories request a fish size corresponding to the legal mesh-size of 5 inches or more. Thus, if a fisher targets Nile perch, the market requirements reduce the probability of this fisher violating the regulation by 0.51 units compared to the others.

For the deterrence variables, it is notable that all four subjective probabilities have the expected negative sign. They are also statistically significant, except for the probability of being taken to court after being arrested $(P R O B D A C) .{ }^{9}$ The insignificance of the PROBDAC variable may reflect that it is easy to avoid punishment by offering bribes, which is what the fishers stated in the interviews. All of the 459 fishers in the sample had experience of being arrested and $40 \%$ of them had used bribes to avoid being taken to court. In fact, $23 \%$ of those who had not violated the regulation during the last twelve months had used bribes when being arrested to avoid the problems of being taken to court, even though they were innocent. In the group of persistent violators, 93\% avoided being taken to court when arrested by the use of bribes. The difference between illegal and legal mesh size values of catch per crewmember effort $(D C P U M)$ is significant in explaining the violation decision. According to the ARRERATE ${ }^{10}$ variable, fishers who have experienced higher arrest rates tend to violate less. The variable SEEN is negative and significant, which indicate that the more often they have seen officials the less likely they are to violate. When it comes to social and legitimacy variables, their influence on the violation rate seems reduced compared to their importance for the decision of whether a fisher would be a non-violator or violate the regulation. Those who do, in fact, violate are still influenced by the perceived compliance rate among their colleagues; if they think many others violate, then the

\footnotetext{
${ }^{9}$ PROBDACG is only significant at the $13 \%$ level, so strictly speaking it is not significant.

${ }^{10}$ In order to reduce the problem of correlation between being arrested and violation frequency, the number of arrests was divided by the number of violating months.
} 
probability to comply is low. Similarly, they tend to comply if their perception is that fishers' views are considered in the regulation design, and if they believe that the regulation benefits all fishers.

A fundamental question to address is whether the deterrence or the social and legitimacy variables can be excluded. If we look at the adjusted $\mathrm{R}^{2}$ excluding social, deterrence, and legitimacy, or all three groups of variables, then the full model is reduced from 0.36 to $0.31,0.26$, and 0.21 , respectively. We further explore this issue using the Fstatistics for various regressions. The null hypothesis that all social and legitimacy variables are zero can be rejected at the $5 \%$ level of significance (2.253, critical level 1.88), while zero deterrence variables can be rejected at the $1 \%$ level $(5.172,2.51)$. Hence, we conclude that both deterrence and social and legitimacy variables are vital in explaining the behavior of the alternating violators.

\section{Policy Implications and Conclusions}

This analysis of the Tanzanian Lake Victoria fishers' compliance gives support to the traditional economics of crime model. One striking finding is that the subjective probabilities stated by the artisan fishers significantly work as a determinant for the middle group of alternating violators. The results also show that the extension of the basic deterrence model, which includes moral development, legitimacy, and considerations regarding the behavior of others in the fishery, leads to a richer model with substantially higher explanatory power for the decision between being a non-violator or possibly a violator. For the middle group, i.e., those who sometimes violate, the moral and legitimacy variables have less impact than to those in the non-violating group but are still significant in explaining the behavior of this 
group. Our interpretation is that once you have broken the rules, moral and legitimacy factors are less important in mitigating the violation rate.

A potential problem in a study like this is that of self-serving bias when measuring attitudes and opinions, by asking individuals and having them provide answers to motivate their actual behavior. The fishers in this study were generous with their answers, even the answers concerning their own violation rates. For the fishers concerned with their reputations or selfimages, reducing the stated violation rate instead of trying to find arguments for violation in the legitimacy and moral variables seems more plausible. For those who are non-violators, the incentive to for instance state that fishers' views are taken into account to defend that they are obeying the rules seems even weaker; in the case of strategic answers we would rather expect to find insignificant variables. Unfortunately, we could not find any data from the authorities on violation rates to cross-validate the reported violation rates, which could have been an indicator of misrepresentation in the data.

In the Lake Victoria fishery, as indicated by previous studies on fishery compliance, there is a small group of persistent violators. These fishers seem to have found that constant violation is the most beneficial strategy irrespective of deterrence variables or legitimacy and social variables. Whether the fishers have undertaken any particular evasion investments is unknown, but in principal they always use the illegal mesh size and use bribes to reduce or escape from penalties. The fishery management implication for systematic violations would be temporary withdrawal of the fishing license and even incarceration if the violations are repeated. However, this is more easily said than done. According to Transparency International (TI), the TI Corruption Perceptions Index 2004 (TI, 2004) finds that 60 countries score less than 3 out of 10 , indicating rampant corruption. One such country is Tanzania, with an estimated value of 2.8 and a confidence range of 2.4-3.2, securing place 
90 of 146. The frequent use of bribes is also confirmed by our study; all of the respondents had experienced arrest and $40 \%$ had used bribes to avoid being taken to court. In fact, in the group of non-violating fishers, $23 \%$ used bribes to avoid the bother of court proceedings and the risk of being convicted despite being innocent. Given the fact that all fishers had experienced arrest, the high perceived overall probability of being punished (7\%), and the existing corruption indicate that inspection officers' personal gain from bribes may even reinforce the arresting frequency. How to handle corruption is beyond the scope of this study, but the general policy recommendation is to increase the individual firms' ability to commit to nonbribery, which can be supported via measures like disseminating information about corrupt practices and recognizing those who are doing a good job by resisting corruption (Svensson, 2003). One critique of the deterrence model is that fishers comply with the regulation to a larger extent than predicted by the model. Such a critique does not apply to this fishery, where the overall violation rate of $29 \%$ is substantially higher than the rate previously found in developed and newly industrialized countries. There are two potential explanations as we see it. First, Tanzanian fishers are poorer than previously studied colleagues and cannot afford moral and legitimacy concerns to the same extent. Second, the ubiquitous level of corruption most likely has a negative impact on compliance. When even those who obey the rules are arrested and must use bribes to avoid being taken to court, we expect the "distaste of crime" to be low.

Compliance with the minimum mesh size does not solve the overcapitalization problem that follows from the open access regime, but given that the minimum is large enough, female fish will be able to reproduce at least once and the overfishing will not lead to complete stock depletion (Townsend, 1986). If all fishers start to use the small mesh size, there is an increasing risk that female fish will be caught even before reaching sexual maturity, leading to a complete stock collapse (Clark, 1990). The local Beach Management 
Units, which have been initiated to enhance community participation in surveillance and management, seem to have been successful in putting an end to the use of poison or dynamite, but not in achieving minimum mesh size compliance. According to our results, the BMUs do not have an impact on fishers' decisions of being non-violators, i.e., always obeying the mesh size regulation. While fishers agree that poison or dynamite can easily harm, oneself or those nearby, their perception of the stock deterioration mechanism may be vaguer. Such misperceptions of bioeconomics were found in an experiment with people from the fisheries sector in Norway (Moxnes, 1998). Development of the BMUs and the understanding of the importance of conserving the juvenile fish seem to be low-cost management options. Combined with increased deterrence activity, they may even contribute to more sustainable fishing practices in Lake Victoria.

\section{References}

Anderson, L.G., and Lee, D.R., (1986) "Optimal Governing Instruments in Natural Resources Regulation: The Case of the Fishery". American Journal of Agricultural Economics, 68(4): 679-90.

Becker G.S., (1968), “Crime and Punishment: An Economic Approach”. Journal of Political economy, Vol. 76, issue 2, pp 169-217.

Brundy, A., and T. Pitcher (1995), 'An analysis of species changes in Lake Victoria: Did the Nile perch act alone'? In Pitcher, T.J. and P.J.B Hart (Eds). The impact of Species Changes in African Lakes. London: Chapman and Hall, Fish and Fisheries Series No. 18 pp 136.

Clark, C. W. (1990) Mathematical bioeconomics: The optimal management of renewable resources, Second edition Pure and Applied Mathematics series. New York: Wiley.

Eggert, H. and A. Ellergård (2003). "Fishery control and regulation compliance: a case for Co-management in Swedish commercial fisheries" Marine Policy 27 525-533.

Erlich, I., (1973) 'Participation in Illegitimate Activities: A Theoretical and Empirical Investigation' Journal of Political Economy 81:3, 521-565.

Feldman, P. (1993) The Psychology of Crime. New York: Cambridge University Press.

Furlong, W.J. (1991) "The Deterrence Effect of Regulatory Enforcement in the Fishery". Land Economics. 67 (Feb): 116-29

Gaviria, A. (2000) 'Increasing Returns and the Evolution of Violent Crime: The Case of Colombia'. Journal of Development Economics, 61 (1):1-25.

Greene, W (2000), "Econometric Analysis" $4^{\text {th }}$ Edition. Pretence Hall, London

Hatcher, A., S. Jaffry., O. Thébaud, and E. Bennett (2000) "Normative and Social Influences Affecting Compliance with Fishery Regulations". Land Economics. 76(3): 448-461. 
Hatcher, A. and D.V. Gordon (2005) 'Further Investigations into the Factors Affecting Compliance with U.K. Fishing Quotas' Land Economics 81(1):71-86.

Heckman, J.J. (1979)"SSample Selection Bias as a Specification Error". Econometrica, Vol.47(1) 153-162.

Ikiara, M.M (1999) "Sustainability, Livelihoods, Production and Effort Supply in a Declining Fishery" The case of Kenya's Lake Victoria fisheries. Ph.D thesis, University of Amsterdam.

Kuperan, K., and J.G. Sutinen (1998), "Blue Water Crime: Legitimacy, Deterrence and Compliance in Fisheries". Law and Society Review, 32:309-38.

Kudhongania, A.W and D.B.R. Chitamwebwa (1995) 'Impact of environmental change, species introductions and ecological interactions on the fish stocks of Lake Victoria' In Pitcher, T.J and P.J.B. Hart (eds) The impact of Species Changes in African Lakes.

Lake Victoria Fisheries Organization (LVFO), (1999), The LVFO Strategic Vision (19992015).

Lake Victoria Fisheries Organization (LVFO), (2004) ‘A Status Report on Frame Surveys', LVFO Secretariat, Jinja, Uganda.

Liao, T.F., (1994) "Interpreting Probability Models: Logit, Probit and other Generalized Linear Models. Sage University paper series on Quantitative Application in Social Science, 07-101. Thousand Oaks, CA. Sage.

Lokina, R.B. (2004) 'Technical Efficiency and Skipper Skill in Artisanal Lake Victoria Fisheries'. Paper presented at the XIII Annual Conference of the European Association of Environmental and Resource Economists, Budapest, Hungary, $25^{\text {th }}-28^{\text {th }}$ June.

Manski, C., (1978) 'Prospect for Inference on Deterrence Through Empirical Analysis of Individual Behavior' In Economic Models of Criminal Behavior, ed. J.M. Heineke. Amsterdam: North-Holland Publishing Company.

Milliman, S.R. (1986) 'Optimal Fishery Management in the Presence of Illegal Activity' Journal of Environmental Economics and Management, 13 (4):363-81.

Moxnes, E. (1998) 'Not only the Tragedy of the Commons Misperceptions of Bioeconomics. Management Science. 44(9): 1234-1248.

Pauly, D., (1996) 'ITQ: the assumptions behind a meme' Reviews in Fish Biology and Fisheries 6:109-12.

Robinson, P.H. and J.M. Darley (1997), 'The Utility of Desert', Northwestern University Law Review 91:453-99.

Ssentongo, G.W., and J. Jlhuliya (2000), 'Report on the Tanzania Fisheries sector review'. FAO sub-regional office for Southern and Eastern Africa, Harare.

Stigler, G.J. (1970) 'The Optimum Enforcement of Laws' Journal of Political Economy, 78(3), p526-36

Sutinen, J., and Andersen, P., (1985) “The Economics of Fisheries Law Enforcement". Land Economics 61(12):387-97.

Sutinen, J. G. and T.M. Hennessey, (1986) 'Enforcement: The Neglected Element in Fishery Management' Natural resources economics and policy applications: Essays in honor of James A. Crutchfield, Eds. E. Miles, R. Pealy, and R. Stokes. Seattle: University of Washington Press.

Sutinen, J.G., and J.R. Gauvin (1989). “An Econometrics Study of Regulatory Enforcement and Compliance in the Commercial Inshore Lobster Fishery of Massachusetts". In Rights Based Fishing, ed P. Neher, R. Arnason, and N. Mollet. NATO ASI Series E: Applied Sciences 169. Dordrecht: Kluwer.

Sutinen, J.G., and Kuperan, K., (1999) "A socio-economic theory of regulatory Compliance”. International journal of Social Economics, 26,1/2/3:174-93. 
Svensson, J. (2003) 'Who Must Pay Bribes and How Much? Evidence from a Cross Section of Firms' Quarterly Journal of Economics 118 (1): 207-30.

Townsend, R. E. (1986) 'A Critique of Models of the American Lobster Fishery' Journal of Environmental Economics and Management, 13(3), 277-91.

Transparency International (2004). http://www.transparency.org/cpi/2004/cpi2004.en.html\#cpi2004

Tyler, T.R., (1990) Why People Obey the Law. Yale University Press, New Haven and London.

UNEP, 2002, State of the Environment and Policy Retrospective: 1972-2002.

Wilson, D.C (1995), "Country fieldwork report of the socio-economic research on Lake Victoria, Tanzania, by the program on the lakes of East Africa 1994-1995

World Bank, 2002. "Linking Poverty Reduction and Environmental Management: Policy Challenges and Opportunities", Washington DC, World Bank. 